\title{
Interaction entre I'antigène CD4 et le virus du SIDA
}

Les lymphocytes $T$ peuvent être divisés en deux groupes principaux selon qu'ils expriment l'antigène de surface CD4 (anciennement dénommé T4) et interagissent avec des cellules exprimant les molécules de classe II du complexe majeur d'histocompatibilité (CMH), ou bien expriment l'antigène CD8 (anciennement dénommé $T 8$ ) et interagissent avec des cellules exprimant les molécules de classe I du CMH. Les cellules $T-C D 4^{+}$sont avant tout des lymphocytes " $T$ helper ", alors que les cellules $T-C D 8^{+}$sont principalement des lymphocytes $T$ suppresseurs et cytotoxiques. L'antigène CD4 sert non seulement de récepteur pour les molécules de classe II du CMH mais aussi pour l'agent du SIDA, le virus $H I V$, ce qui explique le lymphotropisme d'HIV et l'immunodéficience secondaire à la destruction des lymphocytes T-CD4* (voir Lexique $\mathrm{m} / \mathrm{s} \mathrm{n}^{\circ} 2$, vol. 3, p. 106). HIV est aussi capable d'infecter des cellules cérébrales et de provoquer des désordres neurologiques secondaires d̀ une encéphalite subaiguë. Maddon et al., du laboratoire de Richard Axel, ont isolé en 1985 l'ADN complémentaire et le gène codant pour l'antigène CD4 [1]. Très récemment, ces auteurs sont parvenus à transférer dans divers types de cellule l'ADN complémentaire CD4 complet intégré dans un vecteur rétroviral et contrôlé par le LTR rétroviral 5' [2]. Ils ont ainsi démontré que l'expression de l'antigène CD4 à la surface de cellules humaines non lymphocytaires était suffisante pour rendre ces cellules sensibles à l'infection virale. Il semble que la glycoprotéine de surface d'HIV interagisse directement avec CD4, cette liaison provoquant l'endocytose du virus.

Physiologiquement, le messager codant pour CD4 est assez fortement exprimé dans certaines régions du cerveau, notamment dans la région corticale des lobes frontaux. Dans le cerveau, cependant, la taille de l'espèce majoritaire de messager $C D 4$ est $1,8 \mathrm{~kb}$ au lieu de
$3 \mathrm{~kb}$ dans les cellules $T-C D 4^{+}$et l'on ne sait pas si ces deux espèces $d^{\prime} A R N$, de 3 et $1,8 \mathrm{~kb}$, peuvent toutes deux coder pour l'antigène: Quoiqu'il en soit ces travaux démontrent que, dans les cellules humaines, l'expression de l'antigène CD4 est nécessaire et suffisante à la sensibilité des cellules à l'infection par HIV. CD4 se comporte comme un récepteur pour le virus, se liant à sa glycoprotéine de surface; la fixation du virus à CD4 est suivie d'une internalisation du complexe par endocytose. Le neurotropisme d'HIV pourrait être expliqué par l'expression du gène CD4 dans des cellules cérébrales.

A. $\mathbf{K}$.

1. Maddon PJ, Littman DR, Godfrey M, Maddon DE, Chess L, Axel R. The isolation and nucleotide sequence of a cDNA encoding the T-cell surface protein T4: a new member of the immunoglobulin gene family. Cell 1985 ; 42 : 93-104.

2. Maddon PJ, Dalgleish AG, Mc Dougal JS, Clapham PR, Weiss RA, Axel R. The T4 gene encodes the AIDS virus receptor and is expressed in the immune system and the brain. Cell $1986 ; 47: 333-48$

\section{口u BRÈVES}

L'existence d'une séquence 3 ' non codante située en aval du codon stop n'est pas absolument constante dans les messagers eucaryotiques. Ainsi, le messager de la thymidylatesynthase de souris se termine par le codon stop $U G A$, immédiatement suivi de la séquence d'acide polyadénylique. Au niveau génomique, le résidu $\mathrm{A}$ du codon $U G A$ n'existe pas, et est donc ajouté après la transcription avec les autres résidus adényliques. Le signal de polyadénylation, situé 21 bases avant le codon stop, est "ATT AAA "; il code pour les résidus isoleucine et lysine.

[Jenh CH et al. Proc Natl Acad Sci USA 1986 ; 83 : 8482-6.] \\ DQ BRÈVES}

La recombinaison in vivo de deux virus non virulents peut donner naissance à une espèce hautement pathogène, c'est ce que viennent de démontrer des chercheurs californiens. Des souris infectées par l'une ou l'autre de deux souches peu pathogènes d'Herpès ne font pas d'affection sévère, alors que l'inoculation simultanée des deux souches provoque la mort de $61 \%$ des animaux. Dans la majorité des cas, on retrouve dans le cerveau des animaux morts une nouvelle espèce de virus, hautement pathogène, dérivée des deux souches avirulentes par un processus de recombinaison. Ce modèle d'acquisition de la virulence par recombinaison virale pourrait-il s'appliquer à l'agent du SIDA, le virus HIV ? [Javier RT, et al. Science 1986 ; 234 : 746-8.]

La publication par l'URSS de certaines données démographiques, interrompue depuis plus de dix ans, vient de reprendre et permet de faire le point. En 1985, l'espérance de vie en URSS est de 64 ans chez l'homme ( 71 en France) et de 73 ans chez la femme (79 en France). Le taux de mortalité infantile ( 0 à 1 an) est globalement de 26 p. 1000 (8 p. 1000 en France), avec des variations importantes d'une République à l'autre. Pour apprécier le fait que cette mortalité apparaisse plus élevée qu'en 1970, il faut tenir compte des progrès de l'enregistrement dans les Républiques d'Asie, les données anciennes étant peu fiables. La fécondité moyenne est de 2,4 enfants par femme (1,85 en France) et n'a pas baissé depuis 1970. Elle varie de 2,1 en Europe à plus de 5 au Tadjikistan. La population de l'URSS (279 millions au 1.1.1986) s'est accrue à un rythme annuel moyen de 1,15\% au cours des 30 dernières années. [Blum A. Population et Sociétés. Décembre 1986, $n^{\circ} 208$.] 